\title{
FIGHTING AGAINST HARMFUL RUMOURS, OR FOR FISHERIES?
}

\author{
Evaluating framings and narrations of risk \\ governance in marine radiation after the \\ Fukushima nuclear accident
}

Leslie Mabon and Midori Kawabe

\begin{abstract}
This chapter explores the narration of risk in marine produce from Iwaki in Fukushima Prefecture, Japan. The release of radioactive matter into the Pacific Ocean following the 2011 earthquake, tsunami and nuclear disaster in north-east Japan is the largest-ever accidental marine pollution incident. In Fukushima, this has affected coastal communities for whom fishing is economically, socially and culturally significant. We explore the interplay between two different narratives around radiation risk in marine produce. One concerns dispelling 'harmful rumours' around safety of marine produce, claiming that as marine radiation can be known and controlled, raising concerns over safety is harmful to the recovery of affected locales. The second is an alternative narrative emerging from local-level actors (municipal government, fisheries cooperatives, NGOs) focused on the inherent uncertainty associated with complex coastal ecosystems. Transparency and participation in data collection act to develop collective understandings of an 'acceptable' level of uncertainty. Drawing on field research from Iwaki, we illustrate that while these two narratives are distinct, they are by no means polar opposites. Common to both are wider questions about trust in the people and institutions producing knowledge about water and about what can be known with certainty in water environments.
\end{abstract}

\section{Introduction}

In this chapter, we evaluate the narration of risk, uncertainty and safety in marine produce in Fukushima Prefecture, Japan, since the 2011 nuclear disaster. Given the overarching theme of this volume, we pay particular attention to how the issue of contaminated water is narrated. Or, more specifically, how the potential for contaminated water to find its way into fish and seafood and then into humans is framed and managed by decision-makers at different levels. The more standard way to narrate this issue involves one-way communication of 'science' to educate consumers and wider society that marine produce from Fukushima is safe. However, an alternative narrative, which has emerged at the municipal or local level, framing post-disaster fisheries as a sociocultural issue as well as an economic issue, and openly acknowledging remaining uncertainties, may offer a more nuanced way of understanding how marine produce fits with post-disaster recovery.

We assess these issues by focusing on Iwaki in the south of Fukushima Prefecture. Iwaki is one of two fishing districts within Fukushima-the other being SomaFutaba in the north - and is itself divided into numerous fishing ports (see Figure 2.1). Iwaki, like Soma, has been moving towards restarting its coastal fisheries. Its coastal areas were badly affected by the 2011 tsunami, and the coastal waters off 
Iwaki received much of the water-borne contamination from the nuclear plant. The material on which the ideas in this chapter are based comes from research the authors have been undertaking in Iwaki since spring 2011, involving field research in the form of interviews, focus groups, science cafes, ethnography, and participant observation, as well as desk research into how different actors narrate radiation risk in policy documentation, promotional and marketing literature, and the media.1 While in this chapter we put forth empirical issues, it is worth briefly outlining the theoretical underpinnings behind our arguments. Our approach borrows heavily from the 'risk governance' school of thought (International Risk Governance Council 2005; Renn 2008). Just as environmental governance in a wider sense involves resolving conflicts through institutional arrangements that may facilitate or limit the use of environmental resources (Adger et al. 2002), we understand 'risk governance' in the environmental context to mean decision-making that balances a range of different and often competing perspectives on environmental risk. This is especially crucial for situations of high environmental and social complexity like contamination of a marine environment, where even 'experts' may disagree on the science underlying the issue (Pellizzoni 2003) and different understandings of what is meant by 'risk' (risk versus uncertainty versus indeterminacy and so on) may be at play (Riesch 2012). The result of this, Kasperson (2014) summarises, is that the increasing complexity of environmental risks comes alongside a decline in trust in scientists and policymakers who may previously have been expected to manage risks on behalf of society. It is because of this decline in trust that Kasperson (2014) believes there is a greater need for risk communication, which he understands as a deliberative and dialogic process towards reaching the most appropriate decisions for society on managing risk and uncertainty. Nonetheless, it is widely argued that in spite of the emergence of a large body of scholarly thought on the relationship between science and society, this 'risk communication' in practice often remains a one-way top-down process (e.g. Wynne 2006; Arvai 2014) concerned with correcting misunderstandings and bringing publics and stakeholders to understand and accept the techno-scientific 'facts' underpinning an issue.
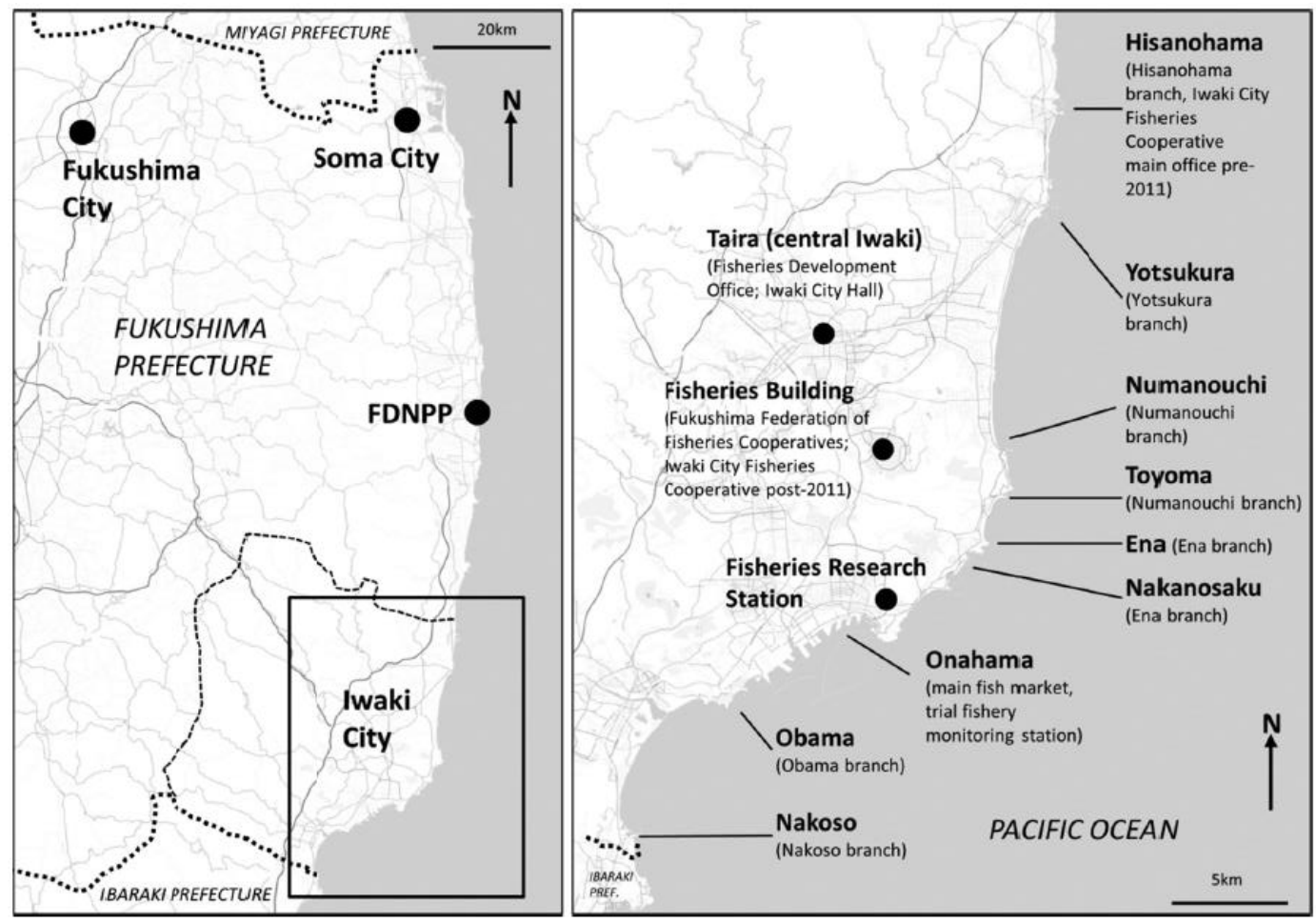

FIGURE 2.1. Location of Iwaki within Fukushima Prefecture (left) and ports and key fisheries locations within Iwaki (right). Source: Adapted from map tiles by Stamen Design, under CC BY 3.0. Data by OpenStreetMap, under ODbL (n.b. permission obtained for reproduction). 
Apart from a range of different perspectives on what constitutes an acceptable level of risk, there may also be differing understandings of what 'risk communication' means and what its role ought to be in the risk governance process. What we are interested in this chapter is how different actors frame risk and uncertainty in a highly complex environmental situation, how their understanding of 'risk communication' may affect this framing, and how well these narratives are suited to balancing the range of competing conceptualisations of risk that may be at play. We return to these ideas in Section Discussion to theorise from our findings.

\section{Background: 11 March 2011 and thereafter}

On the afternoon of 11 March 2011, an earthquake of magnitude 9.0 off the coast of north-east Japan triggered a large tsunami. The cumulative effects of this earthquake and tsunami left over 17,000 people either dead or missing, with the most severe effects being felt in Iwate, Miyagi and Fukushima Prefectures. This event also took offline the cooling systems at the Fukushima Dai'ichi nuclear power plant (FDNPP) located on the coast of Fukushima Prefecture and operated by the Tokyo Electric Power Company (TEPCO). This in turn led to overheats and hydrogen explosions in three of the plant's reactors, releasing radioactive contamination over the land and sea of Fukushima Prefecture and beyond. The resulting contamination led to over 120,000 people being evacuated from their homes, many of whom are still unable to return as the radiation dose around their homes remains above safe limits. More significant for our study, however, is the fact that 70-80 per cent of the radiation emitted from the FDNPP fell over the north-west Pacific Ocean (Yoshida and Kanda 2012). Highly contaminated water leaked into the Pacific Ocean in the aftermath of the disaster, and further leaks (albeit of less contaminated water) followed, as on-site contamination found its way into groundwater and/or drainage systems. Further, space for prefabricated tanks to store treated water, previously used to keep the FDNPP's reactors cool, has been running out, and in spring 2021 the Japanese Government agreed to plans to release this treated water into the sea. There have also been questions over the effectiveness of the ice wall commissioned by TEPCO to stop contamination from the reactors leaking into groundwater, with its chief architect admitting in spring 2016 that some water will still leak through the wall (Japan Times 2016). We will return to these issues later in the chapter, as they are important in illustrating the difference between viewing the FDNPP situation as 'under control' or narrating it as an ongoing incident that has not yet been resolved.

\section{Effects on fisheries}

The tsunami itself was a major contributing factor in the stoppage of fisheries in Fukushima immediately after the disaster. Port infrastructure, boats, equipment, and fishers' homes were washed away or destroyed, making the swift restart of fisheries impossible in any case. However, with the large radiation releases from the FDNPP, the Fukushima Prefecture Federation of Fisheries Cooperative Associations (FPFFCA) formally elected to temporarily suspend fisheries days after the tsunami. It is also interesting to note that Fukushima's coastal fisheries have never technically been embargoed or 'banned' outright by the Japanese government. Rather, marketing and distribution restriction directives were issued by the national-level government on species of fish landed 2 in Fukushima Prefecture after the discovery in 2011 of samples exceeding the national regulatory threshold. Between April 2011 and 2012, over 40 per cent of the sampled fish were similarly found to exceed the Japanese regulatory limit for radioactive caesium (Buesseler 2012). Hence, the stoppage of full-scale commercial coastal fisheries in Fukushima is described as a 'voluntary suspension' as it follows a directive rather than a law (FPFFCA 2016). This national regulatory threshold for radioactive caesium was initially 500 Becquerels/kilogram (Bq/ $\mathrm{kg}_{3}$ ); however, in April 2012, this was lowered to $100 \mathrm{~Bq} /$ $\mathrm{kg}$. Marine contamination has been monitored by the Fisheries Agency of Japan on the coast and out at sea, and by the plant operator TEPCO in the immediate vicinity of the FDNPP. Further, Fukushima Prefecture's Fisheries Research Section is responsible 
for monitoring of fish stocks, seawater and bottom sediment post-disaster (Wada et al. 2013). As Fukushima Prefecture's own research vessel had foundered in the tsunami, fishers themselves supported this emergency monitoring at first, by catching fish in their own boats and bringing them to the prefectural laboratories for analysis.

If radioactive caesium is not detected in fish species over a period of many months during this monitoring, species may be released for trial fishing operations. These trials, which run at less than one-fifth of pre-disaster capacity, aim to encourage fishers to resume fishing activities and also monitor the uptake of Fukushima produce as it returns to market, by brokers and consumers. The release of species for trial fishing operations is determined by dialogue between fishers, fisheries cooperatives, brokers, prefectural and national government scientists and policymakers, and academics. As of spring 2019, 211 species had been released for operations (Fukushima Prefectural Government 2019). However, the restart of commercial trials proceeded at a faster pace in Soma-Futaba than in Iwaki due to lower levels of contamination and closer proximity to markets and consumers in the large city of Sendai. Consumer uptake of marine produce from within Fukushima also remains divided.

It is worth mentioning that the perception of the risk of marine contamination from the Fukushima disaster became an international issue. Other nations (e.g. China, Korea, Taiwan) banned the import of fish not only from Fukushima, but also in some cases from the north-east or even all of Japan. In late 2015, Canadian scientist Jay Cullen received death threats and was branded a 'shill' for the nuclear industry, after results from the Fukushima InFORM programme he ran tracking Fukushima radionuclides (Fukushima InForm 2015) suggested that while radionuclides were reaching the west coast of Canada, the risk to human health was virtually non-existent (The Globe and Mail 2015).

This section has aimed to give a broad overview of the effects of the Fukushima disaster on the sea and in particular on the area's fisheries. What we shall now do is evaluate two different narratives and framings for the governance of risk in the recovery of fisheries post-disaster.

\section{Fuhyo higai: harmful rumours}

What we will call the 'standard' narrative of radiation risk in Fukushima produce is the one conveyed by those we would consider to be the most empowered actors, those with the greatest financial resources and the largest influence over policy-making processes and the media. Key actors in this group are the Japanese Government, TEPCO and the government of Fukushima Prefecture. This framing of post-disaster risk from radiation involves the management of rumours about the safety of fruit, rice, vegetables, marine produce, water, and any number of other aspects of the lived-in environment. The set phrase used in Japanese to describe such 'misinformation' and the consequences arising from it is fuhyo higai, normally translated into English as 'harmful rumours'. At base, it refers to the idea that economic harm has been done to Fukushima Prefecture, its produce and the people who produce it as a result of baseless/untrue information discouraging consumers from buying Fukushima produce or visiting the region.

For instance, the prefectural government narrated the situation in Fukushima thus: 'Fukushima Prefecture was hit by a massive earthquake and tsunami which triggered the accident at Tokyo Electric Power Company's Fukushima Dai'ichi Nuclear Power Station and subsequent damage to the prefecture's reputation due to harmful rumours' (Fukushima Prefecture 2011: 3). In a separate document from three years later, TEPCO stated it would continue to compensate local businesses for 'damages due to groundless rumour' (TEPCO 2014: 36). In setting out their own plans for post-disaster recovery, the Ministry of Trade and Environment (METI) too aimed 'to revitalize business operations in affected areas suffering from decreased sales volume due to harmful rumours resulting from the nuclear accident' (METI 2011: 2). 
Implicit in such accounts is the idea that a major barrier to the recovery of the Fukushima economy was the unwillingness of consumers to purchase Fukushima produce or spend time in the area, and that this apprehension was the result of concerns that have no basis. The continuation of this narrative reads that the solution to this problem is 'educating' consumers through the provision of more accurate information in greater volume. Fukushima Prefecture promised to 'promptly and appropriately publicize the safety of Fukushima products at home and overseas by providing accurate information' (Fukushima Prefecture 2011: 16). The Reconstruction Agency aimed for 'eradicating reputational damage from harmful rumors by risk communication' (Reconstruction Agency 2013: 41) and TEPCO likewise targeted 'enhancement of risk communication activities ... to counter harmful rumors' (TEPCO

2014: 11). Particularly interesting to note in this regard is the equation of 'risk communication' with the end goal of engendering understanding or acceptance that the concerns leading to economic harm are unfounded. We return to this in Section 5 to consider slippages between the understanding of 'risk communication' in this narrative of fuhyo higai, versus how risk communication is increasingly understood within the scholarly literature. For now, though, it is sufficient to note that this standard narrative treats risk communication as a one-way transfer of techno-scientific information from the government and operators to the wider society. Given the nature of contemporary environmental risks we outlined at the start of the chapter and the associated requirements for risk governance processes, such a one-way and tightly bound narrative clearly has the potential to be problematic.

The standard narrative of radiation risk in Fukushima focuses on the idea of the underpinning science somehow being known or settled, and that society needs to be brought 'on side' with this message. Such ideas of communicating 'facts' and raising understanding about radiation have equally appeared in some, if not all, physical science-based literature on radioactivity in Fukushima and elsewhere. Nonetheless, notwithstanding the fact that radiation was and continues to be emitted from the FDNPP and hence is present in the environment even if in small amounts, the idea of harmful or baseless rumours perhaps misses an important point- namely, that a narrative of safety based on technical and scientific information may be of limited value if those delivering the narrative are not trusted to be able to competently assess and manage the risks they frame as being manageable (see Wynne 1992). Such a narrative may even backfire if it gives the impression that uncertainties and limitations of human knowledge in comprehending complex technical and environmental systems - which after all contributed to the accident in the first place-have not been given sufficient consideration or taken seriously.

This is particularly evident for fisheries in Fukushima, where a complete lack of trust between fishers and TEPCO over the failure to disclose information over leaks of contaminated water in a timely manner led to a breakdown in communications (Kyodo News 2015), even if the fisheries' stakeholders with whom we spoke did not appear to fundamentally disagree with the content of the data TEPCO produced. The extent to which such lack of trust may work against assurances of safety given by TEPCO is illustrated by the fact that it was not until mid-2015, more than four years after the disaster, that arrangements were made for regular fishers to visit the FDNPP site. The absence of trust between fisheries, their cooperatives and TEPCO thus makes it difficult, if not impossible, to create opportunities like site visits, where fishers may verify TEPCO's claims that the latter is competent to manage water on the FDNPP site.

Indeed, it does not take much to understand why a narrative of absolute safety and 'harmful rumours' may arouse suspicion. The drive by the national government and TEPCO to demonstrate that the situation at the FDNPP is under control and that contamination of the environment is minimal (or at least can be easily remediated) was linked to a wider drive to facilitate the restart and continued use of nuclear reactors elsewhere in Japan (Perrow 2013; Sugiman 2014). Proving safety was also argued to be an important component of the return to normality (Kotting- 
Uhl 2013) by expediting rehabilitation and resettlement, hence reducing the need for the government (and TEPCO) to make compensation payments (AsanumaBrice 2014). Likewise, claims to have the FDNPP situation under control formed a central plank of Prime Minister Shinzo Abe's successful pitch for Tokyo to host the 2020 Olympics - itself widely believed to be the key to the national government's economic growth strategy (Reuters 2013). In other words, those not bearing direct risks to health or livelihood from the accident may be viewed as standing to gain financially by arguing that there is no need for worry and that citizens 'ought' to eat Fukushima produce.

However, scepticism around the wider motives of those who may stand to gain financially from dispelling 'rumours' is not the only reason the fuhyo higai approach (of unequivocal assurances about the safety of Fukushima produce) has come in for criticism. In literature with a more specific focus on the prospects of recovery for Fukushima produce, it has been argued that dismissing societal concerns as mere 'harmful rumours' ignores the complexities about how the region and its produce are perceived post-disaster. This, in turn, may actually hamper the rehabilitation of the region's agriculture and fisheries. Morimoto (2015), for example, argues that the way 'harmful rumours' is deployed in some contexts can actually serve to reinforce a Fukushima/non-Fukushima binary. Morimoto's reasoning is that the phrase 'harmful rumours' is applied almost exclusively to Fukushima and not to other prefectures adjacent to it or the rest of Japan, thereby giving rise to the idea that only produce from Fukushima-and not anywhere else-may be perceived as having the potential to be contaminated. Kimura and Katano (2014) hold that a fuhyo higai framing serves to dismiss concerns over the safety of produce as somehow 'emotional' and irrational, associating the purchasing and consumption of Fukushima produce with heroism and patriotism. Following on from this, we too have argued elsewhere (Mabon and Kawabe 2016) that dismissing consumer concern as 'harmful rumours' overlooks the complexity of factors (e.g. trust, relationships, personal values) that inform legitimate consumer opinion on what constitutes an acceptable level of risk. Interviewed prefectural fisheries scientists, for instance, acknowledged that young mothers in the prefecture had an understandably precautionary view towards radiation risk, and that it was important to show respect for such viewpoints and not force particular groups towards the consumption of local fish. Specific to water, we also note that 'harmful rumours' tends to be applied in a general sense to all aspects of post-disaster Fukushima, treating fisheries in the same way as land-based produce and tourism. This may not be appropriate given the uncertainties and indeterminacies inherent in a marine environment, wherein limitations of financial, logistical and scientific knowledge may make it impossible to create data that guarantee 100 per cent freedom from radiation (see Section 5).

The narrative conveyed by the fuhyo higai approach is that sufficient knowledge and measures are in place to guarantee the absolute safety of produce like fish, if only wider society can be made aware of this. If the idea that Fukushima's produce is risky is only fuhyo higai, it is assumed instead that Fukushima produce is safe.4 In other words, by negating the possibility for produce to be unsafe, its safety is asserted. We suggest, however, that this may actually act as a barrier to attaining fuller revitalisation of activities like commercial fishing in Fukushima. The two main reasons for this are that it (a) may over-simplify complexities and uncertainties around the health effects associated with low levels of radioactive contamination, and more importantly (b) ignores the wide range of factors that may affect how the stakeholders and consumers, on whom the revitalisation of Fukushima depends, come to make decisions on risk. With that in mind, we now evaluate an alternative framing for post-disaster radiation that has emerged within Fukushima itself.

\section{From Fukushima fisheries to Iwaki fisheries to Joban fisheries}

The dominant narrative-or at least the narrative emerging from the actors one would traditionally consider to be most empowered-has centred on building 
understanding that 'Fukushima' and its produce are not harmful. However, an alternative narrative emerging at the local level may offer a different pathway to the revitalisation of fisheries. As we explain, central to this, is the way risk and uncertainty are narrated, and the framing of marine radioactivity not only as a techno-scientific issue, but also as an issue of people and of place. Key in developing this more localised narrative-in our fieldwork at least-has been the municipal authorities and fisheries cooperatives, fisheries scientists, and extension officers working for Fukushima Prefecture, citizen monitoring groups working within the community, and fishers themselves. Crucially, as we elaborate shortly, these are all people who themselves live on the Fukushima coast and hence bear some risk of exposure to radiation. In a refinement of the narrative that there is sufficient knowledge in place to guarantee absolute safety of produce, indeterminacies and uncertainties in marine radiation are opened up to particular scrutiny. This happens not only within Fukushima, but also within the municipality and the fishing district of Iwaki.5 Contrary to the national government upper limit for radioactive caesium of 100 $\mathrm{Bq} / \mathrm{kg}$, the maximum amount permitted by the FPFFCA in marine produce for sale is $50 \mathrm{~Bq} / \mathrm{kg}$. Even within this $50 \mathrm{~Bq} / \mathrm{kg}$, screened samples of fish exceeding 25 $\mathrm{Bq} / \mathrm{kg}$ are sent to the prefectural labs for further tests before being released for sale (and samples exceeding $50 \mathrm{~Bq} / \mathrm{kg}$ are returned to the monitoring-only stage to be reconsidered for trial fisheries at a later stage). These $50 \mathrm{~Bq} / \mathrm{kg}$ and $25 \mathrm{~Bq} / \mathrm{kg}$ levels were set voluntarily by the cooperatives in Iwaki and Soma-Futaba - whose members are themselves fishers-as the fishers wished to take a stricter and more precautionary approach to radiation screening. Indeed, in marketing as well as screening,

fishers who were members of the cooperatives expressed a desire to see more rigorous screening and traceability than that mandated by the central government.

There are also other ways in which publics and those with less formal technoscientific knowledge (such as regular fishers) have shaped the risk governance process within the locality. The process of deciding which fish to monitor, where, and when to release them for trial commercial operations, involved right from the outset, significant levels of input from rank-and-file fishers to gauge motivation and timing for expansion of activities. This involved not only formalised committee meetings, but also informal face-to-face interaction between fishers and fisheries extension officers in the ports. Despite the suspicions raised in the previous section over Fukushima Prefectural Government as an entity, it is also true that individuals and departments within the Prefecture have worked to design and refine monitoring and communication strategies in a way that is responsive to publics' needs (e.g. working collaboratively with outdoor workers and recreationalists to understand how and where to collect radiation data about complex forest environments). Lastly, in Iwaki, formal fisheries' monitoring and screening processes are supplemented with additional periodic monitoring of marine radiation undertaken by the Aquamarine Fukushima laboratory in combination with local citizen group UmiLabo (2018). These data from outside the formal fisheries governance process are collected via rod fishing off piers and by boat off the coast of the FDNPP, driven by pride in local fisheries and also a concern with creating data perceived as 'independent' from the central and regional governments to allow citizens to make informed choices about eating local fish. While the data collected through this informal monitoring do not feed into the fisheries governance process, it is nonetheless uploaded to the UmiLabo blog (www.umilabo.jp/) and is explained to citizens both via blog posts and through public engagement events (see below). What is significant here is that most UmiLabo members possessed little, if any, knowledge of marine radiation prior to 2011, and yet, as citizens, their members have come to act as significant opinion-shapers within the Iwaki community through provision of data and hosting of public events.

Apart from laying down standards, another pivotal activity within fisheries risk governance in Iwaki is the making visible of the processes through which claims to the safety of Iwaki fish can be made. Although a large part of this involves making monitoring and screening data available online in a way that parallels the 'information provision' seen in the fuhyo higai framing, what makes the Iwaki fisheries narrative 
distinct, is transparency in data analysis. The Onahama Danish Trawl Seines Fisheries Cooperative and Iwaki City Fisheries Cooperative carry out screening of trial fisheries' catches in a laboratory situated inside the New Onahama Fish Market. This laboratory is surrounded on three sides by large glass windows, thereby making the process of radiation monitoring visible not only to consumers, but also to fishers bringing in catches. Traceability plays a large part too in UmiLabo's activitiesany member of the public can join the UmiLabo research cruises and catch fish which form part of the organisation's dataset, and at the TabeLabo ('eating lab') events run in conjunction with Aquamarine Fukushima scientists, participants are taken through the whole process of catching, analysing and ultimately eating fish and seafood caught in Iwaki. Information provision and public engagement are of course part of dispelling 'harmful rumours'. The nuance here, however, is that rather than a narrative that says marine produce is safe, it is a narrative of how claims to the safety of some (but crucially not all) Iwaki fish being safe for consumption is made. In short, within Iwaki fisheries, risk and uncertainty are narrated not as something to be ignored or suppressed, but as something to be continually assessed, understood more deeply and lived within. Indeed, a large part of the monitoring and screening undertaken by fisheries scientists at the prefectural research station, by the cooperatives and by groups such as UmiLabo emphasises the heterogeneity of exposure to radioactivity within and between fish species. In turn, what is foregrounded is not only what is known, but also where the remaining limitations in researchers' knowledge lie. The governance of risk and uncertainty at the local level is thus narrated not as a complete assurance as to the safety of all marine produce, but as an ongoing process of refining knowledge that is cognisant of where remaining uncertainties may lie and openly acknowledges the fact that some produce does, in fact, retain the potential to be harmful to humans and hence remains off-limits. In addition to the nature of radiation monitoring and screening at the local level, another central plank of the 'Iwaki fisheries' narrative is the prominence and nature of the people assessing/taking risks within this framing. While trust in the Fukushima Prefecture government as a larger entity appears to have been low, the fisheries scientists and extension officers employed by the prefecture but working 'in the field' within Iwaki-either at the Onahama Fisheries Research Station on the coast or the Fisheries Office in Central Iwaki-appear to be able to garner much higher levels of trust when engaging with fishers themselves on progressing trial fisheries, and when connecting with citizens, brokers and local media on the results of monitoring data. Part of this, we suggest, may be due to the fact that they themselves are 'citizens' living and working in the area and hence are as equally exposed to the risks of radiation from the sea as are the citizens and less empowered stakeholders with whom they engage.

The narrative of knowledge for decisions about marine radiation being produced by those who themselves are risk bearers as well as risk assessors may similarly extend to the screening of trial fisheries catches by local fisheries cooperative employees, many of whom were born and raised within Iwaki and have had to learn the metrics and processes of radiation risk assessment from scratch since the 2011 accident. This may also be seen in the way some of the more localised monitoring groups-such as UmiLabo and Aquamarine Fukushima - make the enjoyment of consuming locally caught produce themselves a key part of their research process. Pride in the quality of their area's fish and seafood, and a related desire to help the recovery of Iwaki fisheries by showing fellow citizens that Iwaki fish are both safe for consumption and delicious, was one of the motivating factors behind the commencement of this citizen monitoring activity (see Mabon and Kawabe 2016). The human dimensions of post-disaster fisheries have been similarly played on by the Iwaki City municipal government, whose TV and textual advertising campaign 'Aiming Towards Return to Full-Scale Iwaki Fisheries' placed a heavy emphasis on showing the fishers, brokers, administrators, and managers involved as 'serious and hardworking' fishers (Iwaki City 2014). This alternative narration of fisheries' recovery being led from within, not only in Fukushima but also in its cities, presents fishing not just as an economic activity, but as something integral to the community and the people within it. Rather than just a 
means of restoring profit for those who were spatially removed from the worst effects of the nuclear disaster, fisheries recovery is thus framed as something that is intrinsically bound up with the recovery of the whole Iwaki community. Recovery is thus both part of the narrative and a goal of the narrative, something to be perpetuated by telling the story of what has been achieved so far.

The Iwaki-led narrative of post-disaster fisheries also draws upon associations with place. Since late 2015, the Iwaki City municipal government's fisheries section has been leading a campaign to evoke the old Joban Mono name historically given to marine produce from the Iwaki area. Key in the narrative which draws on the Joban Mono title are the physical environmental characteristics of the Iwaki coast. The meeting of the warm Kuroshio current from the south and the cold Oyashio current from the north is described as producing nutrient-rich waters that give the fish landed in Iwaki a distinctive flavour (Iwaki City 2015). In much of the discussion about Fukushima's waters and its fisheries post-disaster, the focus has been on how the marine environment may reduce the quality of marine produce. The emphasis has been on the radioactive particles contained within the sea that have the potential to make seafood harmful to eat, or at least create the perception that Iwaki fish may be harmful. The narrative from the municipal level, however, presents the physical environment as something which enhances the quality of Iwaki fish. Further, it is also interesting to note that the Japanese characters used to denote the Joban name一常磐—are a combination of the Japanese characters historically used for the place names of Hitachi (常陸) and Iwaki (磐城). Crucially, however, Hitachi actually belongs in the adjacent Ibaraki Prefecture, hence the name being revived for post-disaster Iwaki fish borrows elements from outside Fukushima. The Joban Mono campaign thus arguably offers a different framing to Fukushima/non-Fukushima fisheries by situating Iwaki and its fisheries in a complex environmental system, one that is influenced by ocean currents and processes from outside the prefecture, yet run by the people within a distinct municipality.

One, of course, has to be careful not to over-celebrate this alternative narrative. The aim of monitoring, screening and trial fisheries is ultimately to return to full-scale commercial operations, and the desired outcome of making monitoring processes transparent and engaging with citizens-for the fisheries cooperatives and prefectural scientists at least-is to encourage people to consume (and thus purchase) Iwaki marine produce. Given that this rehabilitation of fisheries depends on having citizens and brokers prepared to pay for local fish and seafood, these narratives are thus instrumental in increasing the number of people prepared to support Iwaki fisheries. Narration becomes all the more important when we consider that as one always has the option to 'opt-out' by buying fish caught elsewhere, there is little else that can be done to widen the consumer base.

The success of these more precautionary governance initiatives at the local level is still, however, completely at the mercy of decisions taken at the individual or household level as to whether to consume Iwaki fish. There appears to be broad consensus within Iwaki that consumers are divided into two groups-those who are willing to eat locally landed produce, and those who will not, even though monitoring has been undertaken and the relevant information has been provided.

Moreover, what a narrative of incremental and precautionary restarts based on continuous monitoring cannot do is to prevent further changes in the situation at the FDNPP. None of the actors involved in the narrative led from within Iwaki City are in charge of the ongoing process of decommissioning the damaged reactors, working to remove the remaining fuel, safely storing contaminated water and ensuring that radioactive material from the FDNPP site does not find its way into the groundwater or the sea. This is the responsibility of operators and regulators working at the national or international level, such as TEPCO and its subsidiaries and subcontractors, and the various agencies of the Japanese government. And yet the narrative that is being constructed within Iwaki City rests on the premise that 
the worst of the accident is over, that there will be no more large-scale releases of radioactive material into the Pacific Ocean. Thus, the Iwaki-led narrative of fisheries recovery works only if processes outside of its control do not change for the worse. Indeed, the 2015 leaks into the sea and the 2021 decision to release treated water containing tritium and other substances into the Pacific Ocean to reduce pressure on on-site water storage facilities demonstrate that the FDNPP site will retain the potential to be harmful to oceans, fish and by extension, humans for some time yet.

In sum, the alternative narrative of 'Iwaki' fisheries offers a different and more nuanced framing of risk from marine radiation post-disaster, but, in practice, its success or otherwise as a means of progressing debate on the future of Iwaki and Fukushima fisheries may ultimately depend on processes outside the control of fisheries governors. It is the nature of 'communication' about water which we now theorise by connecting our findings to, and building on, extant literature in this area.

\section{Discussion}

Connecting our impressions from Fukushima to wider thinking, we draw out wider lessons for the framing and narration of conflicts related to water that arise from this case study. We reflect on how risk, uncertainty and indeterminacy in the 'science' related to an environmental disaster underpinning a conflict are framed and narrated.

This concerns, more precisely, how the different actors appear to understand risk communication and how this affects the way they narrate (or not) uncertainties and unknowns. As discussed at the start of the chapter, there is a concern that risk communication in practice remains focused on the one-way communication of techno-scientific information in order to garner support for a desired outcome. This may become problematic for the governance of water-related conflicts if, by closing down the discussion to a narrow one-way focus on science and thereby side-lining a wider range of concerns, it gives rise to claims of procedural or epistemic injustice (McLaren 2012). That is, claims to injustice may arise from citizens or stakeholders who feel that a risk governance process designed around the one-way provision of techno-scientific communication does not give them an opportunity to raise concerns arising on, say, ethical grounds (procedural injustice), or if the emphasis on correcting misunderstandings through techno-scientific arguments marginalises arguments based on local or lay knowledge (epistemic injustice). Practically too, attempts to close down risk governance to a narrative of hard science understanding (i.e. understanding based on scientific principles derived from disciplines such as physics, chemistry, biology, and geology, presented as if there is complete agreement within the discipline and little remaining uncertainty) may act as a barrier to reaching solutions. This could happen if 'hard science' arguments create tension-and thus reduce the likelihood of different actors engaging in constructive debate or dialogue-by marginalising or ignoring the viewpoints of those who do not buy into the idea of science being 'settled' or whose concerns stem from, say, ethical, moral or values-based arguments.

Indeed, a useful framework for evaluating how decision-makers and governors may respond to controversy is provided by Sundqvist (2014). Similar to Stirling (2008) on 'opening up' and 'closing down', Sundqvist suggests that the governance of controversy can be framed as either a 'heating up' (opening up the issue to dialogue and debate between decision-makers, scientists, stakeholders, and publics) or a 'cooling down' (allowing a particular course of action to take place through means of allaying or at least calming down concerns). It is too much of a simplification to categorise the national and regional government response to marine radiation in Fukushima as 'cooling down' and the more local response as 'heating up'. After all, local fisheries cooperatives too are striving to restart the sale of fish. Many of those undertaking monitoring of fish stocks outside of the fisheries business (e.g. the UmiLabo citizen 
science group members and the Aquamarine Fukushima scientists supporting them) are motivated to do so because they are personally proud of the quality and heritage of their area's fish and want to support the rehabilitation of fisheries by demonstrating to consumers within Iwaki that local fish are both safe and delicious. However, the assumption underpinning the fuhyo higai approach that there is no cause for concern as to the safety of marine produce-and that not buying or consuming produce out of such concern is hindering the economic recovery of the region-parallels a 'cooling down approach'. That is, it seeks to neutralise concerns by establishing a baseline position that Fukushima fish are safe for consumption. By contrast, governance of risk and uncertainty at the local scale could be seen as more of a 'heating up' (or at least cooling down after heating up) in that decisions over whether or not to proceed with trial fisheries for particular species are taken through a dialogic process, and the aim of engagement with consumers is geared more towards providing them with information to allow them to make their own decision on whether or not to consume local fish and seafood. Sundqvist argues that both 'heating up' and 'cooling down' framings can be successful in the right circumstances. Yet, what we can see in Fukushima fisheries is that the high-level narrative aiming towards 'cooling down' by presenting the science as somehow agreed or settled may be of limited value, or may even broaden scepticism, if those conveying the narrative are not trusted or if significant difference in perception of risk or uncertainty remains.

One may question whether these two narratives can in fact work together to completely close down discussion on risk and safety around Fukushima and the sea. It is certainly true that there is potential for the high-level narrative on absolute safety and the local-level narratives of quality and transparency to work together and provide multiple pathways for citizens to buy into the safety of Fukushima fish. However, it is worth pointing out that many of the individual opinion-shapers informing the narrative of 'Iwaki' fisheries also have a close interest in the nuclear plant through their activities. For instance, manga artist Tatsuta Kazuto frequently brings the eating of Iwaki fish into his Ichi-Efu series, a memoir about the time he spent working at the nuclear plant post-disaster (e.g. Tatsuta 2016). The Encyclopedia of the 1F: A Guide to Decommissioning of the Fukushima Dai'ichi Nuclear Power Station, edited by sociologist Hiroshi Kainuma, juxtaposes the complexities and long-term challenges of decommissioning with guidance on restaurants serving local produce in nearby townships (Kainuma 2016). Such accounts, while not critical of local produce, nonetheless convey nuanced views on the speed and prospects of recovery on the Fukushima coast. In essence, while it is of course the case that there is significant pride among citizen activists in Iwaki fisheries and an aspiration for full revitalisation, it is also true that the Fukushima Dai'ichi Nuclear Power Plant and the continuing complexities around its management are not erased from this narrative. Thus, for the narration of conflicts related to water, an important lesson to draw is to consider what different communicating actors seek to achieve through their framing of techno-scientific risk and uncertainty. Even if conveyed by more empowered actors such as national or prefectural governments, narratives that seek to close down debate and discussion by presenting the underpinning science as somehow settled or agreed upon may backfire if they give the impression that those producing the narrative have given insufficient consideration to uncertainty or indeterminacy. By contrast, even if they are still ultimately based on scientific understanding, narratives that give more situated and nuanced accounts of remaining uncertainties may offer a pathway towards governance that is able to encompass a range of perspectives on what is considered an acceptable level of risk. That is, narrating the process of data collection and analysis, and where the limitations and uncertainties are within this, stops short of telling consumers that their concerns are unfounded and instead leaves them to make their own decision on whether they think the level of risk is acceptable or not. This is especially important for water-related conflicts, where it may be very difficult, if not impossible, to claim that things can be known with complete certainty. The reason for this is that collecting data at sea is an especially costly process, requiring research ships (and crew wages) and technologically sophisticated equipment in the form of diving gear or remotely operated vehicles to collect samples from the 
seabed. Highly specialised skills such as competence in diving may also be required, and additionally, there may be issues pertaining to access to certain areas of waterthis is particularly pointed for Fukushima, where access to the waters around the FDNPP has been strictly controlled. Moreover, the complexity of marine ecosystemswhere the precise movements of currents and the species and material contained within them cannot be known completely-means that there are still limitations to knowledge about how contamination moves through the sea, and how it finds its way into fish and ultimately to humans. All of these factors mean that there are limits on who can collect data in a marine environment, how much data they can collect, and what they can claim based on the analysis of these data. It is because of this inherent uncertainty, and the issues around trust in the risk assessor and differing ideas on what constitutes an acceptable level of risk that it engenders, that the need for risk governance is all the more acute in water conflicts.

\section{Conclusions}

In this chapter, we have presented two different narratives that convey two different approaches to risk governance of marine radiation in Fukushima. One-the fuhyo higai/harmful rumours narrative-places an emphasis on assuring the safety of Fukushima produce based on a linear understanding of 'risk communication'. The other-the Iwaki fisheries/Joban Mono narrative - appears to strive towards transparency in the knowledge-making process and the situation of post-disaster fisheries within a much wider social and environmental context. These narratives should by no means be considered polar opposites. For instance, the provision of environmental monitoring data (i.e. the basis on which claims to safety are made) is increasingly becoming part of dispelling 'harmful rumours'. Likewise, it may well be that the 'Iwaki fisheries' framing emphasises respect for differing viewpoints and strives to allow citizens to come to their own informed decision on whether or not they feel the consumption of locally landed fish is an appropriate risk to take. But the implicit hope within this is that the consumption of local marine produce will increase. It is also imperative not to forget that radiation is a real and harmful phenomenon, one which will continue to be an issue in the Iwaki waters for some time. Hence, a narrative emphasising dialogue and the human dimensions of recovery still has to be supported with scientific research and data on the radiation situation.

Nonetheless, the case of Fukushima and Iwaki fisheries demonstrates that the framing and narration of a conflict can greatly influence not only the outcomes that are reached, but also the process taken to reach that destination. In particular, when it comes to governing conflicts over water with the inherent uncertainty this brings, we suggest looking at whether actors seek to 'open up' or 'close down' controversy through their narratives, which can give analytical insight into what they aim to achieve and how they seek to get there.

In this account, we have not sought to offer answers or solutions to the framing of risk governance in post-disaster Fukushima and Iwaki fisheries. Nor have we sought to offer comment as to the safety or otherwise of the area's fish and seafood. Rather, we have sketched out how two narrations and framings of a water-related conflict can lead to rather different courses of action and give rise to different sets of concerns, even if the envisioned end result of both narratives (in this case, the revitalisation of fisheries) is essentially the same. What may be a valuable next step is to refine the theoretical challenges we raise for water around narrating uncertainty and framing scale through application to other uncertain, value-driven water conflicts in different environmental and cultural contexts.

\section{Notes}

1 Fuller discussions on the methodology used and the kind of analysis undertaken can be found in Mabon and Kawabe (2015).

2 'Landed' in this context refers to the location of the port at which fish caught at sea are brought ashore-that is, where they are taken off the boat after fishing. For coastal 
fisheries in Fukushima, fish 'landed' at a Fukushima port will also have been caught in Fukushima waters, as fishing rights are divided up by prefecture.

3 The Becquerel is the unit of choice for measuring radioactivity in food as it gives a basic physical measure of the amount of ionising radiation released through radioactive decay per kilogram of produce.

4 It is worth noting that the provision of 'evidence' to support the claim that the produce is not harmful, in the form of online radiation monitoring data for various foodstuffs and locations, has started to form a part of the strategies for countering 'harmful rumours'. Fukushima Prefecture is one such institution to have started providing such data in the name of dispelling 'harmful rumours'.

5 Similar processes likewise take place within Soma-Futaba, but here we focus on the narrative that is emerging specific to Iwaki. Hence, when referring to processes or actions specific to this more localised narrative, we talk about 'Iwaki fisheries' rather than 'Fukushima fisheries'.

\section{References}

Adger, W.N., K. Brown, J. Fairbrass, A. Jordan, J. Paavola, S. Rosendo, and G. Seyfang. 2002. Governance for Sustainability: Towards a 'Thick' Understanding of Environmental DecisionMaking, CSERGE Working Paper EDM 02-04. Norwich: University of East Anglia.

Arvai, J. 2014. 'The End of Risk Communication as We Know It', Journal of Risk Research 17(10): 1245-1249.

Asanuma-Brice, C. 2014. 'Beyond Reality-or-An Illusory Ideal: Pro-Nuclear Japan's Management of Migratory Flows in a Nuclear Catastrophe', Asia-Pacific Journal, 12: 47. Buesseler, K. 2012. 'Fishing for Answers off Fukushima', Science, 338: 480-482.

Buesseler, K. 2015. 'Radioactivity in Our Ocean: Fukushima \& Its Impact on the Pacific', Vancouver: Canada, 14 September, https://www.youtube.com/watch?v=zaXKLz3X9aU (accessed 22 April 2019).

Fukushima InForm. 2015. 'Fukushima Contamination Detected at Shoreline in British Columbia', http://fukushimainform.ca/2015/04/06/fukushima-contamination-detectedatshoreline-in-british-columbia/(accessed 26 March 2019).

Fukushima Prefectural Federation of Fisheries Cooperative Associations. 2016. 'The Undertaking of Trial Fisheries in Fukushima Prefecture' (in Japanese), http://www.fsgyoren. jf-net.ne.jp/siso/sisotop.html (accessed 11 March 2016).

Fukushima Prefecture. 2011. Vision for Revitalization in Fukushima Prefecture, Fukushima Prefectural Government: Fukushima City, https://www.pref.fukushima.lg.jp/download/ 1/vision_for_revitalization.pdf (accessed 26 March 2019).

Fukushima Prefectural Government. 2019. 'Marine Seafood' Fukushima Prefectural Government: Fukushima City, https://www.pref.fukushima.lg.jp/uploaded/attachment/ 317965.pdf (accessed 26 March 2019).

International Governance Council. 2005. White Paper on Risk Governance: Towards an Integrated Approach, Geneva: IRGC.

Iwaki City. 2014. The Story of the Trial Fisheries (in Japanese), http://misemasu-iwaki.jp/ $\mathrm{cm} /$ index.html (accessed 20 March 2015).

Iwaki City. 2015. What is Joban-Mono? (in Japanese), http://misemasu-iwaki.jp/joban/ item/A5guidebook-201510.pdf (accessed 20 March 2016).

Japan Times, 2016. 'Fukushima No. 1 Plant's Ice Wall Won't Be Watertight, Says Chief Architect', Japan Times (Online Edition) http://www.japantimes.co.jp/news/2016/04/29/ national/fukushima-plants-new-ice-wall-will-not-be-watertight-says-chief-architect/\#. VyQeMdKLTIW (accessed 26 March 2019).

Kainuma, H. 2016. Encyclopedia of the 1F: A Guide to Decommissioning of the Fukushima Daiichi Nuclear Power Station (in Japanese). Tokyo: Ohta Books.

Kasperson, R. 2014. 'Four Questions for Risk Communication', Journal of Risk Research, 17(10): 1233-1239.

Kimura, A.H. and Y. Katano. 2014. 'Farming after the Fukushima Accident: A Feminist Political Ecology Analysis of Organic Agriculture', Journal of Rural Studies, 34: 108-116. Kotting-Uhl, S. 2013. 'Japanreise 2013: Tag 7 - Fukushima Daichi', http://kotting-uhl.de/ site/japanreise-2013-tag7 (accessed 3 February 2015).

Kyodo News. 2015. 'Fukushima Prefecture Fisheries Association: "The Relationship of Trust has Collapsed": Angry Voices at Discharge of Contaminated Rainwater', 25 February 2015 (in Japanese), http://www.47news.jp/CN/201502/CN2015022501001290.html (accessed 30 June 2015).

Mabon, L. and M. Kawabe. 2015. 'Fisheries in Iwaki after the Fukushima Dai'ichi Nuclear Accident: Lessons for Coastal Management under Conditions of High Uncertainty?', Coastal Management, 43(5): 498-518.

Mabon, L. and M. Kawabe. 2016. 'Engagement on Risk and Uncertainty—Lessons from 
Coastal Regions of Fukushima Prefecture, Japan after the 2011 Nuclear Disaster?', Journal of Risk Research. doi:10.1080/13669877.2016.1200658

McLaren, D. 2012. 'Procedural Justice in Carbon Capture and Storage: A Review', Energy and Environment, 23: 345-365.

Ministry of Economy, Trade and Industry. 2011. Challenges and Actions in Economic/Industrial Policies, Tokyo: METI, https://www.manufacturing-policy.eng.cam.ac.uk/documentsfolder/ policies/japan-challenges-and-actions-in-economic-industrial-policies-meti/ at_download/file (accessed 26 March 2019).

Morimoto, R. 2015. 'Interpretative Frameworks of Disaster in Society Close-Up' in A.E. Collins, S. Jones, B. Manyena, and J. Jayawickrama (eds), Hazards, Risks, and Disasters in Society, pp. 324-353. Amsterdam: Elsevier.

Pellizzoni, L. 2003. 'Uncertainty and Participatory Democracy', Environmental Values, 12 (2): 195-224.

Perrow, C. 2013. 'Nuclear Denial: From Hiroshima to Fukushima', Bulletin of the Atomic Scientists, 69(5): 56-67.

Reconstruction Agency. 2013. Towards the Creation of 'New Tohoku' (The Interim Compilation of Discussions). Tokyo: Reconstruction Agency, http://www.reconstruction.go.jp/english/topics/ 2013/08/20130823_Towards_the_Creation_of_New_Tohoku.pdf (accessed 26 March 2019).

Renn, 0. 2008. Risk Governance: Coping with Uncertainty in a Complex World. London: Earthscan. Reuters. 2013. 'Japan Olympic Win Boosts Abe, but Fukushima Shadows Linger', Reuters, 9 September http://www.reuters.com/article/us-olympics-2020-japan-idUSBRE98806P 20130909 (accessed 26 March 2019).

Riesch, H. 2012. 'Levels of Uncertainty', in Roeser, S., R. Hillerbrand, P. Sandin, and M. Peterson (eds), Essentials of Risk Theory, pp. 29-56. New York: Springer. Stirling, A. 2008. "'Opening Up" and "Closing Down": Power, Participation, and Pluralism in the Social Appraisal of Technology', Science, Technology and Human Values, 33 (2): 262-294. Sugiman, T. 2014. 'Lessons Learned from the 2011 Debacle of the Fukushima Nuclear Power Plant', Public Understanding of Science, 23(3): 254-267.

Sundqvist, G. 2014. "Heating up" or "Cooling Down"? Analysing and Performing Broadened Participation in Technoscientific Conflicts', Environment and Planning A, 46(9): 2065-2079. The Globe and Mail. 2015. 'Canadian Researcher Targeted by Hate Campaign over Fukushima findings', 1 November, The Globe and Mail (Online Edition), http://www. theglobeandmail.com/news/british-columbia/canadian-researcher-targeted-by-hatecampaignover-fukushima-findings/article27060613/ (accessed 26 March 2019).

Tokyo Electric Power Company. 2014. FY2013 Earnings Results (1 April 2013-31 March 2014) Presentation Material. Tokyo: TEPCO, http://www.tepco.co.jp/en/corpinfo/ir/ tool/presen/pdf/140430_1-e.pdf (accessed 26 March 2019).

Tatsuta, K. 2016. Ichi-Efu: An Account of the Cleanup at Fukushima Daiichi Nuclear Power Plant (in Japanese). Tokyo: Kodansha.

UmiLabo. 2018. 'Iwaki Sea Survey Team UmiLabo' (in Japanese), http://www.umilabo. jp/(accessed 26 March 2019).

Wada, T., Y. Nemoto, S. Shimamura, T. Fujita, T. Mizuno, T. Sohtome, K. Kamiyama, T. Morita, and S. Igarashi. 2013. 'Effects of the Nuclear Disaster on Marine Products in Fukushima', Journal of Environmental Radioactivity, 124: 246-254.

Wynne, B. 1992. 'Misunderstood misunderstanding: social identities and public uptake of science', Public Understanding of Science, 1(3): 281-304. doi:10.1088/0963-6625/1/3/004 Wynne, B. 2006. 'Public Engagement as a Means of Restoring Public Trust in Science: Hitting the Notes, but Missing the Music?', Community Genetics, 9(3): 211-220.

Yoshida, N. and J. Kanda. 2012. 'Tracking the Fukushima Radionuclides', Science, 336: 1115-1116. 